J. Lake Sci. (湖泊科学), 2006, 18(3):305-311

http:// www. jlakes. org. E-mail: jlakes@ niglas. ac.cn

(c) 2006 by Journal of Lake Sciences

\title{
云南抚仙湖鱼类资源现状与变化
}

\author{
熊 飞 ${ }^{1,2}$, 李文朝 ${ }^{1}$, 潘继征 ${ }^{1}$, 李爱权 ${ }^{1}$, 夏天翔 ${ }^{1}$ \\ ( 1 :中国科学院南京地理与湖泊研究所,南京 210008) \\ (2: 中国科学院研究生院, 北京 100039)
}

摘 要:2004 年 3 月 - 2005 年 7 月对抚仙湖鱼类资源进行了调查,共采集到鱼类 33 种,隶属于 13 科 30 属,其中土著鱼类 14 种,特有鱼类 4 种. 渔获物种类主要为: 太湖新银鱼、云南倒刺鲃、抚仙鲇、黄颖鱼和鲫等. 抚仙湖鱼类群落结构发生了 显著变化,䱚浪白鱼等土著鱼类资源严重衰竭. 与 1995 年相比, 11 种土著鱼类未采到,其他鱼类增加 5 种.

关键词:鱼类资源; 土著鱼类;资源现状; 抚仙湖

\section{Status and changes of fish resources in Lake Fuxian, Yunnan Province}

XIONG Fei ${ }^{1,2}$,LI Wenchao ${ }^{1}$,PAN Jizheng ${ }^{1}$, LI Aiquan ${ }^{1} \&$ XIA Tianxiang ${ }^{1}$

( 1 :Nanjing Institute of Geography and Limnology, Chinese Academy of Sciences, Nanjing 210008,P. R. China)

( 2 : Graduate School, Chinese Academy of Sciences, Beijing 100039,P. R. China)

Abstract: A total of 37 species of fishes belonging to 32 genera and 15 families were collected and identified in Lake Fuxian from March 2004 to July 2005. Among them, 14 species belonged to indigenous fishes and 4 species were endemic to this lake. The main fishes in the catch were Neosalanx taihuensis Chen, Spinibarbus yunnanensis Tsu, Silurus grahami (Regan), Pelteobagrus fulvidraco (Richardson) and Carassius auratus auratus (Linnaeus). There were great changes on community structure of fish fauna in Lake Fuxian, and the resources of the indigenous fishes such as Anabarilius grahami (Regan) decreased severely. Compared with the survey of fish species made in 1995, 11 indigenous species were not collected in Lake Fuxian, while 5 species were found at first.

Keywords: Fish resources; indigenous fishes; status of resources; Lake Fuxian

抚仙湖位于云南省中部, $\mathrm{N} 24^{\circ} 21^{\prime} 28^{\prime \prime}-24^{\circ} 38^{\prime} 00^{\prime \prime}, \mathrm{E} 102^{\circ} 49^{\prime} 12^{\prime \prime}-102^{\circ} 57^{\prime} 26^{\prime \prime}$, 面积 $211 \mathrm{~km}^{2}$, 最大水深 $155 \mathrm{~m}$, 平均水深 $89.6 \mathrm{~m}$, 是我国已知的第二深水湖泊 ${ }^{[1]}$. 最早记述抚仙湖鱼类的学者是英国人 $\operatorname{Regan}^{[2]}$, 我 国学者对抚仙湖鱼类的研究开始于 20 世纪 30 年代 ${ }^{[3]}$,解放后得以全面展开,新种的描述不断增加,并探讨 了鱼类区系的演化 ${ }^{[4-9]}$. $1977-1983$ 年,高礼存等记述鱼类 39 种,隶属于 4 目 15 科 (亚科),其中外来鱼类 9 种 $^{[10]} ; 1988-1995$ 年, 杨君兴等对湖中若干鱼类的生物学特性进行了研究 ${ }^{[11,12]}$, 并对以往资料进行了系 统的分类整理,纠正了一些种的误订或误置,记述鱼类 39 种 (亚种), 隶属于 7 目 14 科 33 属,其中外来鱼类 14 种 $^{[13]}$.

历史调查资料表明:抚仙湖有土著鱼类 25 种, 其中特有鱼类 12 种 $^{[13]}$, 是我国重要的鱼类种质资源宝 库,具有重要的科研和种质保护价值. 自 1995 年杨君兴和陈银瑞报道的抚仙湖鱼类区系至今,已有近 10 年时间了, 在环境变化和人类活动日益加剧的影响下, 抚仙湖生态系统的结构与功能正处在激烈的变化之 中, 其鱼类资源也受到了很大的冲击. 对于整个湖区鱼类区系的现状如何, 发生了哪些变化, 未见报道. 了 解当前抚仙湖鱼类资源的现状及其变化原因,对抚仙湖生物资源保护和管理具有一定参考价值.

* 中国科学院知识创新项目 “云贵高原地区湖泊主要环境问题及对策研究”资助. 2005-08-09 收稿;2005-09-17 收修改稿. 熊飞,男,1977 年生, 博士研究生; E-mail:xf9603@163.com. 


\section{1 调查方法}

2004 年 3 月 -2005 年 7 月,对抚仙湖湖区鱼类进行了全面调查. 对北岸的大河口、西岸的禄充和明星、 南岸的秦家山和隔河、东岸的海口和海镜等地的刺网、地笼渔获物每季进行 1 次跟船调查采样(图 1). 在 银鱼捕捞季节 10 月和 4 月, 对上述地点的银鱼拖网渔获物进行统计分析. 不定期对沿湖钩钓等各种渔获 情况进行调查, 补充采集鱼类标本. 刺网主要为双层刺网, 内层网目 $2 \mathrm{a}=5.6-14.0 \mathrm{~cm}$, 外层网目 $2 \mathrm{a}=7.0$ $-18.4 \mathrm{~cm}$, 高 $1-4 \mathrm{~m}$, 长 $60-150 \mathrm{~m}$; 地笼开口 $50 \mathrm{~cm} \times 50 \mathrm{~cm}$, 长 $6.8 \mathrm{~m}$; 银鱼丝网网目 $2 \mathrm{a}=0.6 \mathrm{~cm}$, 高 $3 \mathrm{~m}$, 长 $100 \mathrm{~m}$; 银鱼拖网网目 $2 \mathrm{a}=0.4 \mathrm{~cm}$, 高 $25 \mathrm{~m}$, 宽 $25 \mathrm{~m}$, 长 $35 \mathrm{~m}$. 共获取刺网渔获物 $98.69 \mathrm{~kg}$, 地笼渔获物 $28.41 \mathrm{~kg}$. 统计银鱼丝网捕捞 12 网次, 银鱼拖网捕捞 30 网次. 生物学测定鱼类近 2000 尾, 每种鱼类均用 $10 \%$ 福尔马林溶液制作标本保存. 鱼类的鉴定参考《云南鱼类志》 ${ }^{[14]}$ 和《中国淡水鱼类检索》 ${ }^{[15]}$. 部分历 史渔业产量等资料从玉溪市抚仙湖管理局获取.

\section{2 结果与分析}

\section{1 鱼类种类}

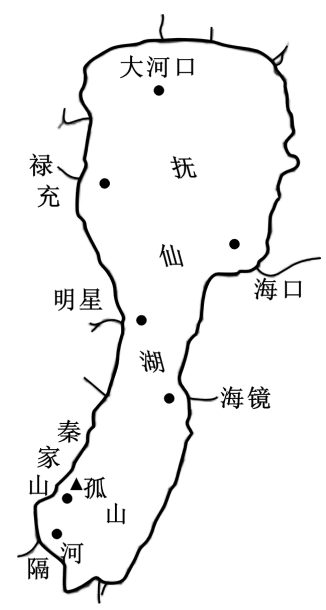

在抚仙湖共采集到鱼类 33 种 (附表 1 ), 隶属于 13 科 30 属. 从表中可以看 出,鱼类组成以鲤科鱼类为主, 共 17 种, 占总种数的 $51.5 \%$; 鳗鲡科、鱾科、鲇科 和鰕虎鱼科各 2 种,各占 $6.1 \%$; 其它 8 科各 1 种, 各占 $3.0 \%$. 在鲤科鱼类中, 鲤 亚科最多,有 5 种, 占鲤科鱼类总种数的 $29.4 \%$, 其次是鲃亚科, 有 4 种, 占 $23.5 \%$. 33 种鱼类中, 土著鱼类 14 种,占 $42.4 \%$, 其中抚仙湖特有鱼类 4 种: 鱇 浪白鱼、抚仙金线鲃、花鲈鲤和抚仙高原鱾; 其他鱼类 19 种,占 $57.6 \%$. 在种数 上,非土著鱼类已经占据了抚仙湖鱼类的主体.

由于抚仙湖为半封闭性湖泊, 与外界河流基本没有鱼类交流, 湖中鱼类大都 属于静水水体鱼类. 常见的土著鱼类有云南倒刺鲃、鲫、抚仙鲇; 常见的其他鱼类 有太湖新银鱼、黄颡鱼、间下鱵、鲦、子陵栉鰕虎鱼、麦穗鱼和棒花鱼等. 除“四大 家鱼”、云南倒刺鲃、花鲇鲤等为大中型鱼类外, 绝大部分为中小型鱼类. 湖中凶 猛性鱼类主要有花鲇鲤、抚仙鲇、乌鳢、黄颡鱼、鳗鲟、欧洲鳗鳕、红鯺原鲌、胡子 鲇等.

\section{2 渔获物组成}

图 1 采样点分布

Fig. 1 Distribution of sampling points

2.2 .1 银鱼捕捞渔获物 太湖新银鱼是抚仙湖的主要经济鱼类, 其产量比较稳 定, 是沿岸农民的一项重要创收来源. 银鱼的捕捞有丝网和拖网两种方式,丝网 的选择性强, 银鱼规格非常整齐, 全长范围 $47-72 \mathrm{~mm}$, 平均全长 $60.05 \pm 6.99$ $\mathrm{mm}$, 体重范围 $0.34-1.15 \mathrm{~g}$, 平均体重 $0.66 \pm 0.22 \mathrm{~g}$. 拖网捕捞的银鱼大小不一, 全长范围 22-65 mm, 平均全长 $45.85 \pm 9.67 \mathrm{~mm}$, 最大体重 $0.87 \mathrm{~g}$, 最小体重 $<0.01 \mathrm{~g}$, 平均体重 $0.28 \pm 0.21 \mathrm{~g}$. 银鱼拖网在岸边用拖拉机头拉, 拖程约 $4 \mathrm{~km}$, 平均渔获物为 $39.11 \mathrm{~kg}$, 其 中太湖新银鱼的重量百分比达 $96.5 \%$, 其它杂鱼约占 $3.5 \%$, 主要是一些中上层和沿岸浅水区小型鱼类, 以 间下鱵为主,有时抚仙高原鳅、黄䁫鱼和子陵栉鰕虎鱼有一些. 在银鱼拖网中曾经出现的种类还有:鲫、鳗 鲡、泥鲀和棒花鱼等.

2.2.2 刺网渔获物 刺网是抚仙湖的主要渔具之一. 抚仙湖北岸和南岸为冲积平原, 鱼类组成比较单一, 主 要为: 黄颡鱼、鲫、抚仙鲇和间下鱵. 如北岸梁王河口一次刺网渔获物 $1776.83 \mathrm{~g}$ 中, 只有黄颡鱼和鲫两种, 前者的重量百分比为 $57.24 \%$, 后者为 $42.76 \%$. 西岸和东岸为陡峭的岩石, 鱼类种类多, 特别是土著鱼类比 较丰富,主要为:云南倒刺鲃、抚仙鲇、鲦、黄颡鱼、鲫、鱇浪白鱼、抚仙金线鲃等 $($ 表 1 ).

从表 1 可以看出,云南倒刺鲃是刺网最主要的渔获物,不管是重量还是尾数,都占绝对优势, 重量百分 比达 $46.79 \%$, 其次是抚仙鲇、黄颡鱼、鲦和鲫, 四者共占渔获物总重量的 $41.12 \%$, 鱇浪白鱼、抚仙金线鲃、 花鲇鲤等特有鱼类主要分布在这一带, 分别占渔获物总重量的 $2.32 \% 、 1.84 \%$ 和 $0.60 \%$. 值得注意, 在渔获 物中常出现金鱼,约占总重量的 $2.65 \%$. 
表 1 抚仙湖禄充 - 明星刺网渔获物组成 ${ }^{1)}$

Tab. 1 Catch composition of gill net near Luchong and Mingxing of Lake Fuxian

\begin{tabular}{|c|c|c|c|c|c|}
\hline 种 类 & 重量 $(\mathrm{g})$ & 重量百分比 ( \%) & 平均体长 $(\mathrm{mm})$ & 平均体重 $(\mathrm{g})$ & 尾 数 \\
\hline 云南倒刺鲃 & 24756 & 46.79 & $147.1 \pm 40.2$ & $73.9 \pm 71.1$ & 335 \\
\hline 抚仙鲇 & 7154 & 13.52 & $236.1 \pm 83.3$ & $216.8 \pm 238.0$ & 33 \\
\hline 黄颡鱼 & 5023 & 9.49 & $142.2 \pm 31.6$ & $59.8 \pm 26.2$ & 84 \\
\hline 鲦 & 4797 & 9.07 & $136.6 \pm 17.2$ & $39.0 \pm 16.1$ & 123 \\
\hline 鲫 & 4785 & 9.04 & $161.3 \pm 34.5$ & $145.0 \pm 57.5$ & 33 \\
\hline 乌鳢 & 1876 & 3.55 & - & $938.0 \pm 794.8$ & 2 \\
\hline 金鱼 & 1404 & 2.65 & $122.3 \pm 77.1$ & $156.0 \pm 111.3$ & 9 \\
\hline 鰁浪白鱼 & 1227 & 2.32 & $141.3 \pm 13.2$ & $36.1 \pm 8.9$ & 34 \\
\hline 抚仙金线鲃 & 974 & 1.84 & $113.4 \pm 14.8$ & $33.6 \pm 17.2$ & 29 \\
\hline 花鲈鲤 & 316 & 0.60 & $142.5 \pm 30.1$ & $39.5 \pm 18.5$ & 8 \\
\hline 红鯺原鲌 & 234 & 0.44 & $133.0 \pm 19.7$ & $39.0 \pm 16.2$ & 6 \\
\hline 棒花鱼 & 173 & 0.33 & $108 \pm 21.4$ & $24.7 \pm 13.6$ & 7 \\
\hline 云南光唇鱼 & 100 & 0.19 & $135.0 \pm 18.7$ & $50 \pm 10.1$ & 2 \\
\hline 泥鳅 & 64 & 0.12 & $131.0 \pm 26.9$ & $32.0 \pm 8.5$ & 2 \\
\hline 麦穗鱼 & 15 & 0.03 & $77.5 \pm 10.6$ & $7.6 \pm 1.9$ & 2 \\
\hline 中华鳑鮍 & 9 & 0.02 & 68.0 & 9.0 & 1 \\
\hline 总计 & 52907 & 100 & - & - & 710 \\
\hline
\end{tabular}

1) 调查时间为 2005 年 7 月 11 日 - 26 日,每日作业时间约 $10 \mathrm{~h}$, 双层刺网 4 条: 内层网目 $2 \mathrm{a}=5.6 \mathrm{~cm}$, 外层网目 $2 \mathrm{a}=7.0 \mathrm{~cm}$, 高 $3 \mathrm{~m}$, 长 $150 \mathrm{~m}$ (2 条); 内层网目 $2 \mathrm{a}=6.4 \mathrm{~cm}$, 外层网目 $2 \mathrm{a}=14.0 \mathrm{~cm}$, 高 $1 \mathrm{~m}$, 长 $60 \mathrm{~m}$ (1 条); 内层网目 $2 \mathrm{a}=8.0 \mathrm{~cm}$, 外层网目 $2 \mathrm{a}=15.0 \mathrm{~cm}$, 高 $3 \mathrm{~m}$, 长 $80 \mathrm{~m}$ (1 条).

表 2 抚仙湖秦家山地笼渔获物组成 ${ }^{2)}$

Tab. 2 Catch composition of fishing cage in Qingjiashan of Lake Fuxian

\begin{tabular}{cccccc}
\hline 种 类 & 重量 $(\mathrm{g})$ & 重量百分比 $(\%)$ & 平均体长 $(\mathrm{mm})$ & 平均体重 $(\mathrm{g})$ & 尾 数 \\
\hline 棒花鱼 & 1427 & 34.97 & $60.2 \pm 20.5$ & $12.2 \pm 9.8$ & 117 \\
子陵栉鰕虎鱼 & 759 & 18.60 & $50.0 \pm 12.7$ & $6.6 \pm 4.0$ & 115 \\
欧洲鳗鲡 & 500.00 & 12.25 & 678.0 & 500.0 & 1 \\
麦穗鱼 & 377 & 9.24 & $71.4 \pm 10.6$ & $16.4 \pm 7.3$ & 23 \\
红鯺原鲌 & 283 & 6.93 & $68.5 \pm 17.3$ & $10.9 \pm 7.8$ & 26 \\
鲫 & 212 & 5.19 & $78.5 \pm 38.5$ & $30.3 \pm 25.9$ & 7 \\
抚仙鲇 & 155 & 3.80 & $121.5 \pm 48.5$ & $77.6 \pm 68.4$ & 2 \\
黄颡鱼 & 110 & 2.70 & $156.5 \pm 0.5$ & $55.2 \pm 6.1$ & 2 \\
黄默鱼 & 82 & 2.01 & $36.9 \pm 2.5$ & $2.0 \pm 0.4$ & 41 \\
胡子鲇 & 75 & 1.84 & $118.0 \pm 70.0$ & $37.6 \pm 35.1$ & 2 \\
中华鳑鮍 & 67 & 1.64 & $52.5 \pm 5.5$ & $6.7 \pm 2.3$ & 10 \\
抚仙高原鳅 & 34 & 0.83 & $6.3 \pm 4.0$ & $6.7 \pm 2.4$ & 5 \\
总计 & 4081 & 100 & - & - & 351 \\
\hline
\end{tabular}

2) 调查时间为 2004 年 10 月 29 日,8 条地笼,作业时间 $24 \mathrm{~h}$. 
虽然只有 1 条, 但体重达 $500.00 \mathrm{~g}$, 占渔获物总重量的 $12.25 \%$, 其余 6 种鱼类尾数和重量均不多, 一起占渔 获物总重量的 $12.82 \%$. 调查表明, 不同地点地笼的渔获物存在一定的差异, 如在隔河口附近地笼中有杞麓 鲤, 而没有抚仙鲇、胡子鲇、抚仙高原䱊、欧洲鳗鲟等,其他种类基本相同.

\section{3 鱼类群落结构变化}

抚仙湖鱼类群落结构正在发生显著变化, 土著鱼类资源在逐渐衰退, 其他鱼类的种类和种群数量急剧 上升. 2005 年与 1995 年 ${ }^{[13]}$ 的调查结果相比(图 2), 土著鱼类种数减少 11 种, 降幅 $44.0 \%$, 特别是特有鱼 类减少 8 种,降幅 $66.7 \%$,而其他鱼类种数则增加 5 种, 增幅 $35.7 \%$.

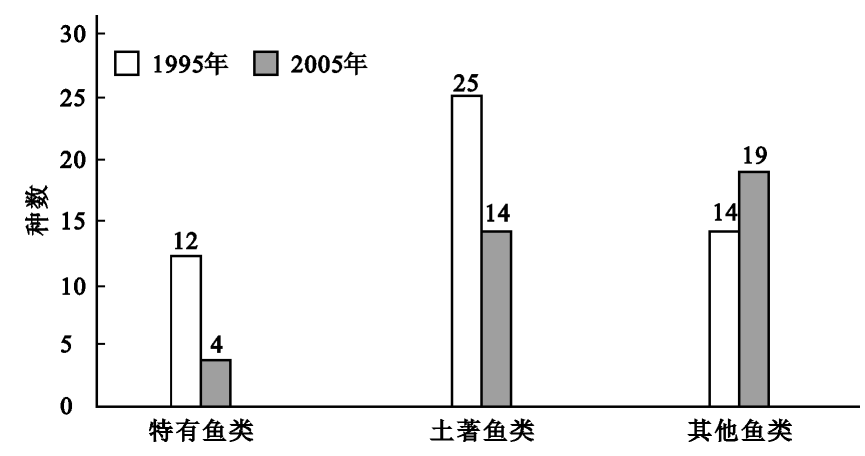

图 22005 年与 1995 年抚仙湖鱼类种数对比

Fig. 2 Comparison of the number of fish species in Lake Fuxian between 1995 and 2005

在原来的 25 种土著鱼类中, 有 11 种未采到: 小鳔长身鱊、抚仙四须鲃、常氏四须鲃、云南瓣结鱼、长须 盘鮈、长鳔盘鮈、鳞胸裂腹鱼、侧纹云南鲀、褚氏云南鳅、钝吻云南鳅、副鳅, 均为抚仙湖土著鱼类, 除小鳔长 身鱊、长鳔盘鮈和侧纹云南鱾外, 其余 8 种均为抚仙湖特有鱼类. 原来曾是抚仙湖常见鱼类的花鲈鲤和云 南光唇鱼,已变成了偶见种. 鱇浪白鱼和抚仙金线鲃种群数量较大, 曾是抚仙湖的主要渔业对象, 如今已近 濒危. 云南倒刺鲃和抚仙鲇属大型鱼类, 是抚仙湖的主要经济鱼类, 如今资源也严重衰退, 个体小型化, 渔 获物中个体主要为 $1-2$ 龄. 1995 年抚仙湖有外来鱼类共 14 种,2005 年调查发现又新增了一些种类, 如日 本鳗鲡、欧洲鳗鲡、黄颡鱼、胡子鲇、红鯺原鲌等.

\section{4 资源量变化}

抚仙湖鱼类资源的变化, 以土著鱼类鱇浪白鱼资源的衰竭和外来鱼类太湖新银鱼资源的增长最为典型 (图 3). 20 世纪 80 年代鱇浪白鱼全湖产量 300-400 t,90 年代初开始持续下降, 到 1998 年产量为 $10.4 \mathrm{t}$, $2000-2004$ 年年产量约 0.5-1 t. 相反, 太湖新银鱼作为一个典型的外来鱼类, 从星云湖经隔河自然进入抚 仙湖后, 仅几年时间就形成了稳定的种群, 1990-2004 年平均产量达 1554 t. 20 世纪 80 年代末, 银鱼拖网 渔获物的抽样结果显示, 每捕起 $1 \mathrm{~kg}$ 的太湖新银鱼, 就会捕起 $2-4 \mathrm{~cm}$ 长的鱇浪白鱼 250 尾 $^{[16]}$, 如今在银 鱼捕捞过程中基本上见不到鱇浪白鱼,可见鱇浪白鱼已经到濒临灭绝的状态.

\section{2 结论与讨论}

(1) $2004-2005$ 年调查抚仙湖鱼类 33 种, 隶属于 13 科 30 属, 其中土著鱼类 14 种, 占 $42.4 \%$, 其他鱼类 19 种, 占 $57.6 \%$, 在种数上, 非土著鱼类已经占据了抚仙湖鱼类的主体.

(2) 抚仙湖鱼类群落结构发生了显著变化,土著鱼类减少,其他鱼类增多, 与 1995 年调查资料比,11 种 土著鱼类未采到,其中包括 8 种特有鱼类, 其他鱼类增加 5 种.

(3) 抚仙湖主要渔获种类为:太湖新银鱼、云南倒刺鲃、抚仙鲇、黄颡鱼和鲫等. 鲦、间下鱵、棒花鱼、子 陵栉鰕虎鱼、麦穗鱼等种群数量也较大. 太湖新银鱼是抚仙湖的主要渔业对象, $1990-2004$ 年平均产量约 $1554 \mathrm{t}$, 鱇浪白鱼资源严重衰竭, 年产量由上百吨降至约 $0.5-1 \mathrm{t}$. 


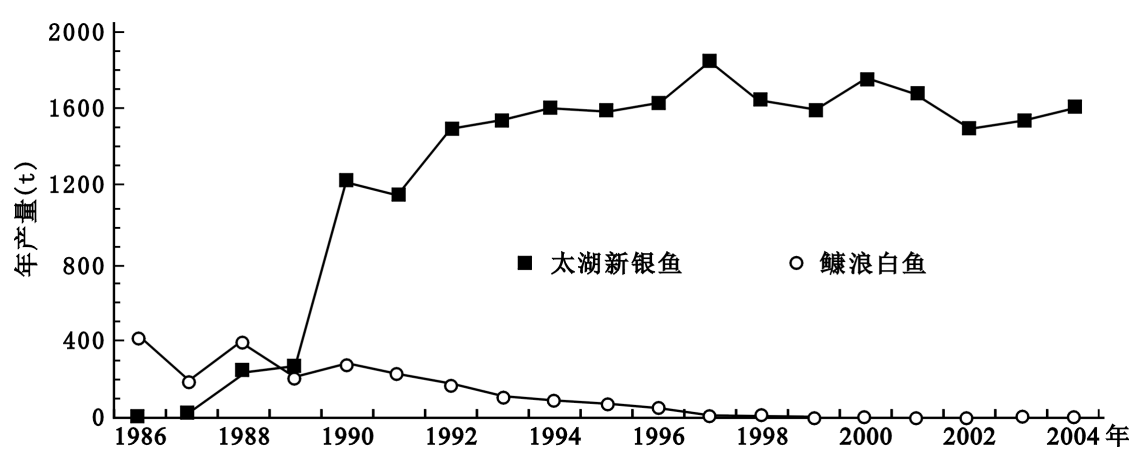

图 $31986-2004$ 年抚仙湖太湖新银鱼和鱇浪白鱼年产量变化 ${ }^{1}$

Fig. 3 Annual yield changes of N. taihuensis and A. grahami in Lake Fuxian during 1986 - 2004

抚仙湖鱼类资源发生变化的原因是多方面的:过度捕捞、外来鱼类的引人、水环境的变化、土著鱼类对 外界环境变化适应能力差等, 其中过度捕捞和外来鱼类是主要原因. 如:1979-1984 年,抚仙湖捕捞鱇浪白 鱼的渔船由 67 只增加到 327 只,1985-1989 年, 捕捞太湖新银鱼的机动船从无增加到 1204 只 ${ }^{[13]}$. 虽然抚 仙湖实施了银鱼季节性开捕、其他鱼类禁捕的管理规定,但在经济利益的驱动下,偷捕现象非常严重. 2005 年 4 月统计,仅西岸五车河沿北岸至东岸禄充风景区一带的各种捕捞渔船就达 1065 只.

抚仙湖外来鱼类种类和数量的增加速度是惊人的,从 1983 年的 9 种增加到 1995 年的 14 种, 2005 年又 新增 5 种. 在 2004-2005 年调查中,除 33 种鱼类之外,在抚仙湖还发现有养殖鱼类罗非鱼 (Oreochromis niloticus (Linnnacus)) 和高背鲫 (C.gaobei var), 观赏鱼类金鱼 (C. auratus (Linnaeus)) 和下口鲇 (Hypostomus multiradiatus Hancock) 等. 对于抚仙湖新增鱼类的来源,虽然现在不会再有人工引种和引种带人的风险, 但 其它途径在不断增加. 鳗鲡和欧洲鳗鲡很可能是海口养殖场逃逸进入抚仙湖的, $1998-2000$ 年此处曾作为 养鳗场, 后来因价格下跌改养鱇浪白鱼, 据渔民反映, 湖中发现这两种鱼近 7-8 年了, 每年在银鱼拖网和地 笼中都能捕到一些. 黄颡鱼、胡子鲇和红鯺原鲌可能是从星云湖迁人的. 近几年来, 黄颞鱼的种群正在逐步 壮大,已成为抚仙湖的主要渔获物之一. 金鱼是信教徒们放生的, 而下口鲇则可能是被弃养的. 目前, 在抚 仙湖鱼类放生现象比较多, 放生种类之多, 数量之大, 对湖泊生态系统存在极大的潜在威胁.

值得注意的是外来鱼类正在逐步占据抚仙湖鱼类的主体，它们会与土著鱼类之间在食物、活动空间和 繁殖等方面存在着激烈的竞争 ${ }^{[17]}$, 凶猛鱼类的引人还会直接捕食土著鱼类. 抚仙湖中新增的 5 种鱼类均 为凶猛性鱼类, 对湖中土著鱼类很可能造成威胁. 20 世纪 90 年代初期, 小型凶猛鱼类红鯺原鲌进入滇池, 种群迅速壮大, 成为滇池的主要渔获物之一, 对滇池的虾类产生了一定的影响 ${ }^{[20,21]}$. 对抚仙湖来说, 红鯺原 鲌也可能对其虾类资源产生一定的负面影响. 但这些凶猛鱼类的进人, 也有可能对湖中小杂鱼种群数量起 到一定的控制作用,究竟有何利弊,需要进一步的研究和监测来证实.

丰富的土著鱼类是抚仙湖生态系统的特色之一,保护好它对维护湖泊生态系统平衡和生物多样性具有 重要意义. 抚仙湖渔业的发展应该坚持以湖泊的综合利用和优化环境为前提,积极发展䱊浪白鱼、抚仙金 线鲃等土著鱼类养殖, 变捕捞渔业为养殖渔业. 为保护抚仙湖鱼类资源, 当地政府已经采取了一系列的措 施, 如鱇浪白鱼人工增殖与种群恢复 ${ }^{[18,19]}$ 、全湖禁机动船、实行季节性开捕等. 在此基础上,建议实施抚仙 湖鱼类资源的全面保护: (1) 加强湖泊的综合环境整治,为鱼类提供一个良好的栖息环境; (2)退垦还湖,保 护好沿岸浅水区域,为鱼类繁殖和幼鱼的受食提供场所; (3) 严格控制外来鱼类进人,加强对外来种人侵的 宣传和预防, 对人侵种进行控制和清除; (4) 对主要的土著鱼类资源进行人工放流和自然增殖; (5) 加强渔 政管理,严厉打击炸鱼、毒鱼、电鱼、偷鱼等现象, 限制网目和作业区,划定鱼类繁殖保护区等. 


\section{4 参考文献}

[1] 中国科学院南京地理与湖泊研究所编. 抚仙湖. 北京: 海洋出版社, 1990 .

[2] Regan C T. On a collection of fishes made by Mr. John Graham at Yunnan Fu. Ann Mag nat Hist, 1904,13 (7) : $150-194$.

[3] Fang B W. Sinocyclocheilus tingi, a new genus and species of Chinese barbid fishes from Yunnan. Sinensia, 1936,7 ( 5 ): $588-593$.

[4] 黎尚豪,俞敏娟,李光正等. 云南高原湖泊调查. 海洋与湖沼, 1963,5(2): $100-110$.

[5] 伍献文主编. 中国鲤科鱼类志(下册).上海:上海人民出版社, 1977: 229-570.

[6] 王幼槐,庄大栋, 高存礼. 云南抚仙湖鱼类鲃亚科鱼类三新种. 动物分类学报, 1982,7(2):216-222.

[7] 李树深. 云南湖泊鱼类的区系及其类型的分化. 动物学报,1982,28(2):160-176

[8] 褚新洛. 云南滇池、抚仙湖、洱海鱼类区系的起源和关系的分析. 高原生物学集刊, 1987,6(6):79 -84 .

[9］黄顺友. 云南盘鮈属 Discogobio 鱼类四新种. 动物学研究, 1989,10(4):355 - 361.

[10] 高礼存, 庄大栋, 郭起治等编. 云南湖泊鱼类资源. 南京: 江苏科学技术出版社, 1990 .

[11] 杨君兴. 云南抚仙湖鱇浪白鱼若干生物学特性的形成及其与湖泊环境演变的关系. 动物学研究, 1992, 13 (4) :353-360.

[12] 杨君兴. 云南抚仙湖鱼类的若干生物学特性及其对湖泊环境的适应. 动物学研究, 1994,15(2): 1 -9.

[13] 杨君兴,陈银瑞编. 抚仙湖鱼类生物学和资源利用. 昆明:云南科技出版社, 1995 .

[14] 褚新洛,陈银瑞主编. 云南鱼类志. 北京:科学出版社, 1990.

[15] 朱松泉编. 中国淡水鱼类检索. 南京: 江苏科学技术出版社, 1995.

[16] 李再云,陈银瑞, 杨君兴. 鱇浪白鱼的生物学及其种群衰减原因分析. 淡水渔业,2003,33(1):26-27.

[17] 谢 平,陈宜瑜. 中国内陆水体生物多样性面临的威胁. 人类环境杂志 (Ambio), 1999,28(8):674 -681 .

[18] 张培清. 鱇浪白鱼池塘人工驯养试验. 水产科技情报,2002,29(6):276-277.

[19] 张培清. 鱇浪白鱼人工繁殖试验. 淡水渔业,2003,33(1):31 - 32.

[20] 陈银瑞, 杨君兴, 周伟等. 滇池红鯺原鲌生物学及对太湖新银鱼渔业的影响. 动物学研究, 1994, 15 (增 刊) :88-95.

[21] 琼 英. 滇池虾类. 水利渔业,2002,22(2):33-34. 
附表 1 抚仙湖鱼类名录 $(2004-2005 \text { 年 })^{1)}$

Appendix 1 Ichthyological survey of Lake Fuxian, 2004 - 2005

种类

I 鳗形目 Anguilliformes

$\mathrm{i}$ 鳗鲡科 Anguillidae

1 鳗鲭 Anguilla japonica Temminck et Schlegel

2 欧洲鳗鲡 A. Anguilla (Linnaeus)

II 鲤形目 Cypriniformes

ii 鲤科 Cyprinidae

雅罗鱼亚科 Leuciscinae

3 青鱼 Mylopharyngodon piceus (Richardson)

4 草鱼 Ctenopharyngodon idellus (Cuvier et Valenciennes)

鲌亚科 Culterinae

5 鲦 Hemiculter leucisculus (Basilewsky)

6 红鯺原鲌 Cultrichthys erythropterus (Basilewsky)

7 鱇浪白鱼 Anabarilius grahami (Regan) ** 鳑鮍亚科 Acheilognathinae

8 中华鳑鮍 Rhodeus sinensis Günther 鲢亚科 Hypophthalmichthyinae

9 鲢 Hypophthalmichthys molitrix (Cuvier et Valenciennes )

10 鳙Aristichthys nobilis ( Richardson)

鮈亚科 Gobioninae

11 麦穗鱼 Abbottina rivularis (Basilewsky)

12 棒花鱼 Pseudorasbora parva (Temminck et Schlegel) 鲃亚科 Barbinae

13 云南倒刺鲃 Spinibarbus yunnanensis Tsu *

14 抚仙金线鲃 Sinocyclocheilus grahami tingi Fang * *

15 花鲇鲤 Percocypris pingi regani ( Tchang) **

16 云南光唇鱼 Acrossocheilus yunnanensis (Regan)* 鲤亚科 Cyprininae

17 杞麓鲤 Cyprinus (Cyprinus) carpio chilia Wu et al. *

18 抚仙小鲤 C. (Mesocyrinus) micristius fuxianensis

Yang et $a l *$

19 鲫 Carassius auratus auratus (Linnaeus) *
种类

iii 鱾科 Cobitidae

20 泥鲉 Misgurnus anguillicaudatus (Cantor) *

21 抚仙高原䱊 Triplophysa fuxianensis Yang et Chu $* *$

III 鲇形目 Siluriformes

iv 鯔科 Bagridae

22 黄颡鱼 Pelteobagrus fulvidraco (Richardson)

V 鲇科 Siluridae

23 抚仙鲇 Silurus grahami (Regan)*

24 胡子鲇 Clarias fuscus (Lacépède)

IV 鳉形目 Cyprinodontiformes

vi 青鳞科 Oryziatidae

25 中华青鳞 Oryzias latipes sinensis Chen, Uwa et Chu $*$

vii 胎鲟科 Peocillidae

26 食蚊鱼 Gambusia affinis (Baird et Girard)

$\mathrm{V}$ 鲑形目 Salmoniformes

viil 银鱼科 Salangidae

27 太湖新银鱼 Neosalanx taihuensis Chen

VI 领针鱼目 Beloniformes

ix 针鱼科 Hemirhamphidae

28 间下鮓 Hyporhamphus intermedius (Cantor)

VII 合鳃鱼目 Symbranchiformes

$\mathrm{X}$ 合鳃科 Symbranchidae

29 黄鳔 Monopterus albus (Zuiew) *

VIII 鲇形目 Perciformes

xi 塘鳢科 Eleotiidae

30 黄䵣鱼 Hypseleotris swinhonis (Gunther)

xii 鰕虎鱼科 Gobiidae

31 子陵栉鰕虎鱼 Ctenogobius giurinus (Rutter)

32 波氏栉鰕虎鱼 C. cliffordpopei (Nichols)

xiil 鳢科 Channidae

33 乌鳢 Channa argus (Cantor) *

$1)$ 标 “*”者为抚仙湖土著鱼类, 其中 “ * * 者为抚仙湖特有鱼类. 